\title{
Error Management Culture and its impact on organizational performance: A moderated mediation model
}

\author{
Bushra Javed \\ Institute of Business Management, Karachi Pakistan \\ Tariq Jalees \\ PAF Kiet, Karachi, Pakistan \\ Gobind M. Herani \\ Dadabhoy Institute of Higher Education, Pakistan \\ Jo-Ann Rolle \\ Business School, Medgar Evers College \\ The City University of New York, USA
}

\begin{abstract}
Keywords
Error management culture, innovative work behavior, organizational learning from errors, and perceived psychological safety
\end{abstract}

\begin{abstract}
Errors are ubiquitous in organizational life and have both positive and negative consequences for organizational performance. Given its importance, we have developed a moderated mediated model to analyze the impact of organizational error management culture on organizational performance by extending error management and share cognition theory. The newly developed model was tested in the service industry of Pakistan. The sample size of the study was 300 employees with a response rate of $96 \%$. The data was collected through a web-based questionnaire. The constructs used in the study were adapted from earlier established scales and measures. Smart PLS was used to test the structural model. Consistent with our hypotheses, the results show that error management culture is positively related to organizational performance and this relationship is mediated by organizational learning from errors and innovative work behavior. The results further demonstrated that perceived psychological safety moderated the direct relationship between organizational learning from errors and error management culture in such a way that relationship is stronger when perceived psychological safety is high. The current study extends the relevant literature and has significant implications for management, theory, and research. For instance, perceived psychological safety in earlier studies has been used as a mediator while we have used it as a moderator. In addition, we tested multi mediation (i.e., organizational learning from errors and innovative work behavior) to empirically validate the relationship of error management culture and organizational performance
\end{abstract}

Corresponding author: Bushra Javed

Email addresses for the corresponding author: javedbushra17@yahoo.com

First submission received: $15^{\text {th }}$ June 2020

Revised submission received: $28^{\text {th }}$ September 2020

Accepted: $2^{\text {nd }}$ October 2020

\section{Introduction}

In many ways, the organizational landscape has undergone dramatic changes in the last two decades. The rising dynamism, and complexity of the contemporary business environment couple with growing technological advancement poses new challenges and opportunities for effectively dealing with errors. Errors are rampant in every organizational life and potentially yield either negative or positive outcomes. Errors in organizations are defined as unintentional and potentially avertable aberrations from organizationally specific standards and goals (Frese and Keith, 2015). With a view to its importance for organizational performance, error literature in recent years has gained momentous growth and is thus regarded as a key phenomenon of burgeoning theoretical and managerial importance (Goodman et al., 2011). 
Errors are prevalent in every organizational activity ranging from product development to service encounters and have certain negative ramifications such as decreased customer satisfaction, create negative publicity, damaged reputation, increase economic costs, elevating psychological stress, job dissatisfaction and in an extreme situation, it results in loss of human life (Zhao and Olivera, 2006). Errors are pervasive not only in various aspects of organizational life but also in the environment, economy, and public policy

Given the significance of errors, the organization has two complementary approaches for dealing with errors namely error prevention (error avoidance) and error management. The former approach takes errors as negative (Reason, 2000; Zhoa 2006) while the latter considers the error as valuable feedback for learning and focused on reducing the negative consequences arises from errors (Chillarege, Nordstrom, \& Williams, 2003). In other words, error management approaches view errors as constructive- that can foster positive outcomes for organizations such as learning and innovation (Lei, Naveh, \& Novikov, 2016).

To implement error management approaches at the organizational level, it is incumbent to establish an error management culture. Error management culture refers to a shared set of norms and values that facilitate error identification, communication, and rectification (Van Dyck, Frese, Baer, and Sonnentag, 2005). Research in this area underlined the fact that error management culture is critical in reducing negative error outcomes (e.g., service interruptions, negative publicity, faulty products, lost human lives) and fostering positive error outcomes, including learning and innovation (Van Dyck et al., 2005). Learning from errors tends to produce several positive outcomes such as performance improvement (Cannon and Edmondson, 2001 ; Heimbeck, Frese, Sonnentag, \& Keith, 2003).

Extending this line of research, organizational scholars argued that by reducing the interpersonal risks, the employees are more likely to learn from their errors (Zhan and Hample, 2016). In this respect, a concept of perceived psychology safety -perceptions of interpersonal risky behaviors (Kahn, 1990) seemed to be an important antecedent of organizational learning from errors (A. C. Edmondson, 2004)

In addition to organizational learning, error management culture may also yield new organizational innovation and processes (Cannon and Edmondson, 2005). It is worthy to note that there is an unexpectedly very limited number of studies on the relationship between innovative work behavior and organizational error management culture. Innovation refers to useful, creative, reliable, and implementable solutions(Argote and Miron-Spektor, 2011). Frese and Keith (2015) argued that innovation and error management culture are complementary to each other. For instance, during the process of exploration and experimentation, new types of errors are being generated (Hammond, Farr, and Sherman, 2011). However, if the organization exhibit error management culture, then efforts are being channelized to reduce the potential damages of errors and prevent the future occurrence of similar errors (van Dyck et al., 2005).

Since error management culture encompasses organizational practices related to detection, communication, sharing, and dealing with errors, it is proposed that organizational error management culture deciphers into positive organizational performance through multi -mediators such as organizational learning from errors and innovative work behavior that not only reduce negative error consequences but also increase positive outcomes of errors i.e., organizational performance. We further proposed perceived psychological safety as a moderator between organizational learning from errors and organizational error management culture.

To summarize, this study aims to answer the questions of whether error management culture affects organizational performance through organizational learning from errors and innovative work behavior. In this way, this study made some valuable addition to the relevant literature. First, by focusing on intervening variables, this study fills the significant research gap by delineating the relationship between error management and learning from errors and between learning from errors and innovative work behavior (Lei, Naveh, and Novikov 2016). Secondly, we advance our understanding that organizations that tolerate mistakes are likely to involve in learning behaviors, and thus add to the growing literature of organizational learning. Thirdly, previous studies on organizational error management culture have been extensively conducted in a high reliable organization such as aviation (Helmreich and Merritt, 2000), medicine (Edmondson, 2004), and manufacturing (Candranegara, 2015.), however less attention has been paid to the service sector that contributes 60 to $70 \%$ to GDP in many 
economies(Coelho and Augusto, 2010). Therefore, this study attempts to fill this gap by focusing on service industries in Pakistan to enhance the generalizability of the results.

\section{Literature Review}

\subsection{Theoretical background}

Organizations are facing various types of errors (Vogus, Sutcliffe, and Weick, 2010). Errors are defined as the avoidable gap between expected and real state (Zhao and Olivera, 2006). Errors may generate potential negative outcomes for organizational life which consequently hampers its performance. Therefore, the study of organizational error merits on its own. Keeping in view the exponential growth of error literature, there is a growing interest of services scholars to investigate the impact of various dimensions of errors on the organizational performance (Guchait, Simons, and Pasamehmetoglu, 2016)

Error management culture is defined as a shared set of organizational norms and practices to collect, communicate, handle, and report error-related information. Share cognition theory proposes that high error management culture facilitates employees in recognizing and managing errors timely(Fiore and Schooler, 2004;Chiu, Hsu, and Wang, 2006). Under the error management culture, employees not only learn from their errors but also from others, which results in effective handling of errors (Mathieu, Heffner, Goodwin, Salas, and Cannon-Bowers, 2000; Cannon and Edmondson, 2001). Various scholars have studied the effect of organizational error management culture on employee's performance (Dimitrova, Van Dyck, Van Hooft, and Groenewegen, 2015). Accordingly, organizations with high management culture have an active mechanism of handling and managing errors by encouraging the employees to report the errors as they happen. While in organizations that have low error management culture, the employees in such organizations are punished and blamed for committing errors (van Dyck et al. 2005). Consequently, employees tend to conceal errors to avoid negative feelings such as shame, fear, and guilt (Zhao and Olivera, 2006).

In the same way, it was found that error management culture encouraged the employees to learn from errors and mistakes by understanding their causes or decrease the negative outcomes that arise from error (Reason,2000). Furthermore, it fosters the climate of innovativeness, exploration, and experimentation via ambidexterity (Van Dyck et al. 2005) a construct that referred to as experimenting and refining new and existing products/services that lead to better performance (Hülsheger, Anderson, and Salgado, 2009). Therefore, we can propose that error management culture can be regarded as an important antecedent of organizational performance in the service industry.

\subsubsection{Error Management culture and Organization Learning from Errors}

Research on learning from organizational errors has gained momentum in recent years (Harteis, Bauer, and Heid, 2012). Argyris, (1976) stated that organizational learning modified the individual behavior ('single-loop learning') or it can also modify an individual's values and norms underlying behavior ('double-loop learning). To enhance the organizational learning from errors, there must have a sound culture of accountability, inquiry (error identification, analysis, and rectification), and trust (interpersonal sharing of the error learning experience) among the employees (Ellis, Caridi, Lipshitz, \& Popper, 1999)

Van Dyck et al. (2005) suggested that there is sharp contrast between error aversion culture (avoiding and concealing errors to reduce negative feelings) and error management culture (characterized by constructive handling and communicating about errors) that encourage an organization ability to learn from errors.

Argyris, (2017) argued that the process of learning comprises identification and rectification of errors, coupled with an active reflection on experience and experimentation. Moving further, learning from errors can drive transformative organizational and individual development(Tucker \& Edmondson, 2003). Previous research suggested that error management culture encourages employees to learn by allowing errors to happen (Keith and Frese, 2011). Organizational learning is characterized as a continuous process of activities such as asking questions, pondering on results, sharing information, discussing errors, and seeking feedback (Frese and Keith, 2015). Organizational scholars have also developed insights on various dimensions of organizational learning and their relationship with error management culture. First, organizational error management culture promotes open communication that 
lead to learning from errors (Van Dyck, 2000; Van Dyck et al., 2005). Second, organizational error management culture provides a secure environment for learning where employees feel safe in committing errors and talking about the errors. Third, error management cultures also incorporate mutual respect, trust, and confidence among the employees that they will not be blamed, punished, or rejected for making and discussing errors that consequently lead to learning from errors (Edmondson, 1999; Hofmann and Frese, 2011). Based on the previous literature, the following hypothesis is proposed

\section{H1: Organizational Error Management Culture is positively associated with organizational learning from errors}

\subsubsection{Organization Learning from Errors and Innovative Work Behavior}

Innovative work behavior (IWB) has been defined as a set of interrelated behaviors for idea creation, idea promotion, and idea realization (Janssen, 2004). There is a growing bulge of studies regarding the relationship between innovativeness and learning orientation (Sinkula, Baker, and Noordewier, 1997). For instance, Calantone et al. (2002) empirically validated the impact of learning orientation on innovativeness. Similarly, Liu, Luo, \& Shi, (2002) also argued that organizational learning is an important predictor of firm innovativeness. In the same line, Hult et al. (2004) empirically validated the argument that organizational learning is a significant antecedent of innovativeness. According to Cefis and Marsili, (2005) organizational learning keeps the organization competitive by introducing new products and services. Given this line of research,(Zohoori, Mohseni, Samadi, and Attarnezhad, 2013) established that organizational learning from errors strongly affects innovative work behavior.

There are quite several studies that empirically validate the indirect relationship of organizational learning from errors with organizational performance through innovative work behavior (Hao, Kasper, \& Muehlbacher, 2012). Extending this line of research, Škerlavaj, Song, and Lee, (2010) researched many Korean organization's innovative cultures and found that learning organization was a significant predictor of service, product, and process innovation. Similarly, various scholars have studied the relationship between organizational learning from errors and innovation processes (S`kerlavaj et al., 2010; Park, Song, Yoon, and Kim, 2014). So, we proposed the following hypothesis

\section{H2: Organizational learning is positively associated with Innovative work Behavior}

\subsubsection{Innovative Work Behavior and Organization Performance}

Innovativeness is an important predictor of business performance (Cooper, 2000). Prior research on organizational performance barely focused on the organization's capacity to innovate (Damanpour, 1991; Hurley and Hult, 1998; Cooper, 2000). Innovativeness is regarded as a predominant strategic tool to promptly deal with changing internal and external environment. In the face of a complex and turbulent environment, an organization must fuel innovativeness for achieving high performance and competitive advantage (Hult et al., 2004).

Owing to the dynamic environment, Innovative work behavior (IWB) of employees is pivotal in achieving better performance(Kanter, 1983). This line of research is further extended by Rosenbusch, Brinckmann, \& Bausch, (2011). They argued that innovativeness significantly contributes to overall organizational performance. Similarly, several authors also underlined the importance of innovative work behavior to improve organizational performance (Van de Ven, 1986 ; Gatignon, Tushman, Smith, and Anderson, 2002; Unsworth \& Parker, 2003). Moreover, Campbell, Gasser, \& Oswald, (1996) empirically demonstrated the positive link between innovative work behavior and organizational performance.

An important line of organizational performance literature also focuses on the organizational climate of innovativeness and organizational performance (Nybakk, Crespell, Hansen, and Lunnan, 2009). Other scholars have also pointed the association of innovative work and organizational performance through gaining competitive advantage (Yuan \& Woodman, 2010 ; Shih \& Susanto, 2011; Janssen et al., 2004; Oldham \& Cummings, 1996 ; Scott \& Bruce, 1994).

H3: Innovative Work Behaviour is positively associated with Organizational performance

\subsubsection{Moderating role of Perceived Psychological Safety}

Psychological safety is defined as the feeling that one is investing oneself into an organizational role without fear of negative repercussion to career, status, or self -image (Kahn, 1990). In other words, 
perceived psychological safety delineates individual perceptions of risks involved in their work environment. In prior studies, perceived psychological safety has been widely studied as a mediating variable in explaining team outcomes, it is also found that perceived psychological safety play a more significant role as a moderator (Sanner and Bunderson, 2013). Furthermore, perceived psychological safety may turn out to moderates the antecedents of organizational performance and organizational learning (Edmondson 2004 ; Salas, Wildman, Burke, \& Goodwin, 2008 ; Sanner and Bunderson, 2013)

A. C. Edmondson \& Lei, (2014) emphasized the role of leaders in fostering perceived psychological safety in the organization. They suggested that a climate of perceived psychological safety empowered employees to identify, analyze and learn the potential hazards that threaten their performance. Moreover, perceived psychological safety facilitates the employees to overcome the learning anxiety- a state where unexpected results thwart one's productive learning (Schein, 1985). Previous researches have shown that perceived psychological safety was conducive to higher performance by reducing risk in proposing a new idea, better team learning, and smoother collaboration in solving problems (West, 1990; Edmondson, 1999). Moreover, perceived psychological safety was found to have a key role in enhancing organizational learning from errors through experimenting and sharing past reflection (Cannon and Edmondson, 2001; West \& Anderson, 1996). However, in a psychologically unsafe environment, people did not report their errors for the sake of blame and punishment. As a result, employees refused to engage in learning behavior which ultimately dampens the organizational performance.

Error management culture on the other hand reduces the negative feelings by acknowledging the inevitableness of errors in organizational life(Lei, Naveh, Nivokov, 2016; Homsma, Van Dyck, De Gilder, Koopman, \& Elfring, 2009 ; Bauer and Mulder, 2007; Edmondson, 1999) and thus enhance the perceived psychological safety of employees. Furthermore, perceived psychological safety was presumed to enrich organizational learning by abolishing obstacles of self-defensiveness, fear, and uncertainty (Edmondson, 1999; Sanner and Bunderson, 2015).

Therefore, based on the above arguments we take perceived psychological safety not as a causal factor but as a moderator to strengthen the relationship between organizational error management culture and learning from errors.

H4: Perceived Psychological Safety moderates the relationship between Error Management Culture and Organizational learning from Errors

\subsection{Conceptual Model}

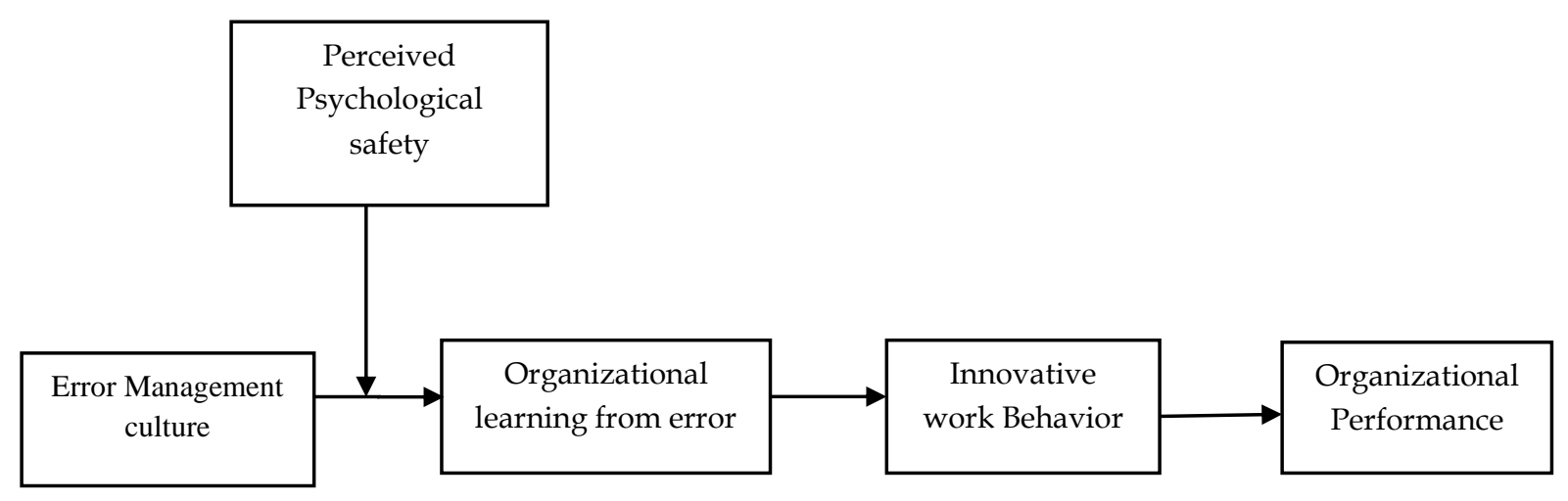

Figure 1 Conceptual Framework

This study proposed that error management culture is positively associated with organizational performance through multi mediators (organizational learning from errors, innovative work behavior) in such a way that error management culture inculcates organizational learning from errors that further leads to innovative work behavior among the employees. We further proposed that that perceived psychological safety moderate the direct relationship between organizational learning from errors and error management culture in such a way that the relationship is stronger when perceived psychological safety is high. 


\subsection{Research Methodology}

\subsubsection{Procedure and Participants}

The target audience for this paper were employees from service industries, located in Karachi. Specifically, service industries were targeted owing to following reasons. First, service industries contribute $55 \%$ to the GDP of Pakistan, with an annual growth rate of $4.3 \%$ and involve $35.1 \%$ of labor forces (Economic Survey of Pakistan, 2015-16). Therefore, given the significance of the service sector in the economy, more studies are required to shed light on error management in services settings (Karatepe, 2012). Second, employees working in different various sectors such as banking, marketing, medical, teaching, and management were taken to enhance the generalizability of the current study. The sample size for this study was 300 employees with a responding rate of $96 \%$. The questionnaire was administered in English and was not translated into native language $U r d u$ as the target audience is well versed in comprehending English. They were informed that the research would be used for academic purpose and their confidentiality is maintained

\subsubsection{Measures \& Scale}

All the measures utilized a five-point Likert scale ( $1=$ strongly disagree; $5=$ strongly agree). The constructs used in this study was adapted from the earliest literature. For measuring, Error management culture scale, the Error Orientation Questionnaire (Rybowiak, Garst, Frese, \& Batinic, 1999) with a twelveitem scale was adapted. Sample items include "For us, errors are very useful for improving the work process", "After an error has occurred, it is analyzed thoroughly", "When an error has occurred, we usually know how to rectify it."

To specifically assess perceived psychological safety, Edmondson,(1999) perceived psychological safety questionnaire was adapted. A sample item includes "If you make a mistake on this organization, it is often held against you", "It is safe to take a risk in this organization."

Employees rated the extent to which their organizations exhibit learning from errors, using seven items based on Putz, Schilling, Kluge, and Stangenberg, (2013) OLE questionnaire. A sample item includes "People in our organization believe that errors at work can be a helpful part of the learning process"

To assess innovative work behavior, a nine-item scale of Janssen (2004) has been adapted. A sample item includes "I search out new working methods or instruments to improve my work"

Organizational performance has been measured using a five-item scale from Delaney and Huselid, (1996). Sample items include "The firm can achieve a high level of customer satisfaction"

\subsubsection{Statistical Analysis}

SMART Analysis was used for statistical analysis. Before testing the structural model, preliminary statistical analysis was carried out which is inclusive of normality, reliability, and missing value analysis.

\section{Data Analysis and Discussion}

\subsection{Respondent profile}

Of the total respondents, $70.3 \%$ (211) were male while $29.7 \%$ (89) were females. The working experience of the employees varies, with $48 \%$ of the employees having 1-5 years of experience followed by $36 \%$ with 6-10 years of experience. Ages of the employees were as high as 55 and as low as 22 with 44 $\%$ of the sample lie between $20-30$ years.

\subsection{Descriptive}

Univariate normality of the constructs was examined through skewness and kurtosis. Table 1 depicts the descriptive statistic.

Table 1 Descriptive Statistics

\begin{tabular}{llllll}
\hline Construct & Mean & Std. Dev & Skewness & Kurtosis & $\begin{array}{l}\text { Cronbach's } \\
\text { Alpha }\end{array}$ \\
\hline Error Management Culture & 4.08 & .234 & 1.09 & 1.04 & 0.70 \\
\hline Innovative work Behaviour & 3.85 & .440 & -.032 & 1.76 & 0.85 \\
\hline Org. Learning from Errors & 3.74 & .534 & -0.648 & 1.96 & 0.88 \\
\hline Organization Performance & 3.63 & .740 & -0.86 & 0.43 & 0.85 \\
\hline $\begin{array}{l}\text { Perceived Psychological } \\
\text { safety }\end{array}$ & 3.35 & .516 & -1.02 & 1.76 & 0.72 \\
\hline
\end{tabular}


Table 1 shows that Error Management Culture $(M=4.08, S D=.23)$ has the highest Skewness $(-1.09)$ followed by Perceived Psychological Safety $(\mathrm{M}=3.35, \mathrm{SD}=.51)$, Organization Performance $(\mathrm{M}=3.63$, $\mathrm{SD}=.74)$, Organization Learning from Errors $(\mathrm{M}=3.74, \mathrm{SD}=.53)$, and Innovative Work behaviors( $\mathrm{M}=3.85$, $\mathrm{SD}=.44)$. On the other hand, the highest Kurtosis(1.96) is of Organization Learning from Errors (M=3.74, $\mathrm{SD}=.53)$ and the lowest kurtosis (.305) is of Organization performance $(\mathrm{M}=3.63, \mathrm{SD}=.74)$. All the Skewness and Kurtosis values ranged between \pm 2.5 indicating that the constructs have no issue with Univariate normality (Byrne, 2013).

\subsection{Construct Validity}

Construct validity is defined as the extent to which a given measure adequately assess the construct it supposed to assess (Nunnally and Bernstein, 1994)

\subsubsection{Convergent Validity}

Convergent validity in the study has been ascertained through composite reliability and average variance extracted. The results are presented in Table 2

Table 2: Convergent Validity

\begin{tabular}{lllll}
\hline Construct & Mean & Std. Dev & $\begin{array}{l}\text { Composite } \\
\text { Reliability }\end{array}$ & AVE \\
\hline Error Management Culture & 4.08 & .234 & 0.79 & 0.50 \\
\hline Innovative work Behaviour & 3.85 & .440 & 0.88 & 0.55 \\
\hline Org. Learning from Errors & 3.74 & .534 & 0.91 & 0.68 \\
\hline Organization Performance & 3.63 & .740 & 0.89 & 0.63 \\
\hline Perceived Psychological safety & 3.35 & .516 & 0.81 & 0.52 \\
\hline
\end{tabular}

The above table indicates that the reliability of each construct is more than 0.7 and the variance explained for each factor is more than 0.5, which means that constructs meet the requirement of convergent validity(Bell, Bryman, \& Harley, 2018).

\subsubsection{Discriminant Validity}

Discriminant validity indicates the uniqueness and distinctiveness of the adopted construct. The results are summarized in Table 3

Table 3: Discriminant Validity

\begin{tabular}{llllll}
\hline Constructs & 1 & 2 & 3 & 4 & 5 \\
\hline Error Management Culture & 0.71 & & & & \\
\hline Innovative work Behaviour & 0.56 & 0.74 & & & \\
\hline Org. Learning from Errors & 0.53 & 0.66 & 0.82 & & \\
\hline Organization Performance & 0.38 & 0.55 & 0.49 & 0.79 & \\
\hline Perceived Psychological safety & 0.42 & 0.19 & 0.47 & 0.35 & 0.72. \\
\hline
\end{tabular}

Table 3 shows that the value of the square root of AVE is higher than the square of each pair of correlation which confirms that the data fulfills the requirement of discriminant validity

\subsection{Path Coefficients}

This study has examined the direct effect as well as an indirect effect. The generated output from SMART PLS is presented in table 4 and 5 and the structural model is presented in figure 2

Table 4: Direct Effects.

\begin{tabular}{lllllll}
\hline No. & Hypothesis & $\mathrm{R}^{2}$ & $\begin{array}{l}\text { Path } \\
\text { Coeff }^{\prime}\end{array}$ & $\begin{array}{l}\text { T } \\
\text { Statis }\end{array}$ & $\begin{array}{l}\text { P } \\
\text { Values }\end{array}$ & Results \\
\hline 1 & EMC - Org. Learning from Errors & 0.18 & 0.20 & 6.57 & 0.00 & Accepted \\
\hline 2 & IWB - Organization Performance. & 0.43 & 0.54 & 21.406 & 0.00 & Accepted \\
\hline 3 & Org. Learning from Behavior -> IWB & 0.40 & 0.65 & 12.093 & 0.00 & Accepted \\
\hline 4 & Per. Psychological safety. -> OLE & 0.30 & 0.23 & 6.67 & 0.00 & Accepted \\
\hline
\end{tabular}

$\mathrm{EMC}=$ Error Management culture, OLE= organizational learning from errors, IWB=Innovative Work Behavior, Per. Psychological safety=perceived psychological safety 
Hypothesis 1 was on the impact of organizational error management culture on organizational learning. The result supports the hypothesis $(\beta=0.20, t=6.57<.05)$ that organizational error management culture is positively associated with organizational learning. Hypothesis 2 proposes that organization learning from errors and innovative work behavior. The results $(\beta=0.65, \mathrm{t}=12.093<.05)$ support the hypothesis that organizational learning from errors is significantly and positively associated with innovative work behavior. Hypothesis 3 was on the impact of innovative work behavior on organizational performance. The results $(\beta=0.65, t=12.093<.05)$ depict that innovative work behavior has a significant and positive association with organizational performance. To analyze the moderating effect of perceived psychological safety on the relationship between organizational learning from errors and error management culture, we conducted moderation analyses with organizational learning from errors as the dependent variable. The results $(\beta=0.23, t=6.67<.05)$ support the hypothesis that perceived psychological safety moderates the relationship.

Table 5: Indirect Effects

\begin{tabular}{|c|c|c|c|c|c|}
\hline No. & Hypothesis & $\begin{array}{l}\text { Path } \\
\text { Coeff }^{\prime}\end{array}$ & $\begin{array}{l}\mathrm{T} \\
\text { Statis }\end{array}$ & $\begin{array}{l}\mathrm{P} \\
\text { Values }\end{array}$ & Results \\
\hline 1 & $\begin{array}{l}\text { EMC -> Org. Learning from Errors-> } \\
\text { IWB }\end{array}$ & 0.13 & 2.31 & 0.01 & Accepted \\
\hline 2 & $\begin{array}{llllll}\text { Per. Psy Safety } & -> & \text { EMC } & \rightarrow & \text { Org.l } \\
\text { Learn.Errors } & & & & \\
\end{array}$ & 0.08 & 2.63 & 0.004 & Acce \\
\hline 3 & EMC -> Org.l Learn. Errors -> IWB-> OP & 0.07 & 2.24 & 0.01 & Accepted \\
\hline 4 & Org.1 Learn. Errors -> IWB -> OP & 0.36 & 9.79 & 0.00 & Accepted \\
\hline
\end{tabular}

The results revealed that both direct and indirect paths are statistically significant. Therefore, the inclusion of organizational learning from errors $(\beta=0.13, t=2.31<.05)$ and innovative work behavior $(\beta=0.36, t=9.79<.05)$ as a mediator between organizational error management culture $(\mathrm{EMC})$ and organizational performance is meaningful. It can be concluded that organizational learning from errors mediates the relationship between error management culture and innovative work behavior. Furthermore, we also found that innovative work behavior mediates the relationship between organizational learning from errors and organizational performance.

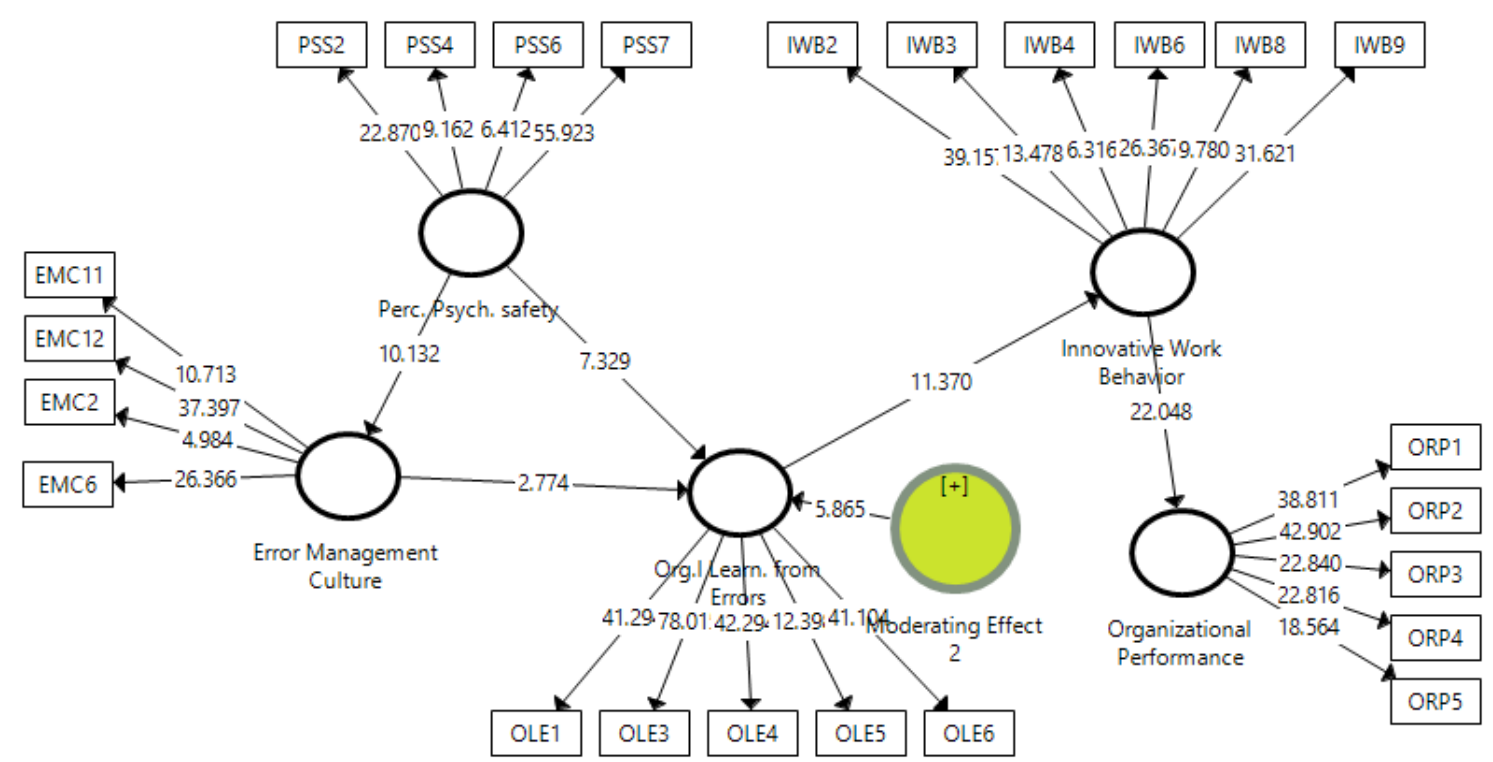

Figure 2 Measurement Model 


\subsection{Discussion}

We advance our understanding of how error management culture predicts organizational performance through multi mediators i.e., organizational learning from errors and innovative work behavior. In doing so, we integrate error management theory with share cognition theory to explain why and how organizational error management culture enhances organizational performance. Specifically, we found that error management culture inculcates learning behaviors among the employees by focusing on the informative aspect of errors. The results are consistent with previous studies where people agree on the positive consequences of errors such as learning, innovation, and resilience (Van Dyck, Frese, Baer, and Sonnentag, 2005; McCune, 1997; Sitkin, 1996; Jones \& O’Brien, 1991). Prior studies also corroborated the notion that learning from errors leads to service timeliness, plant productivity, and survival rates by learning from experience (Reason, 1997; Zhao and Olivera, 2006). We also analyzed that organizational error management culture indirectly leads to a positive organizational performance by fostering organizational learning from errors, understanding the underlying causes of errors, and preventing them from happening in the future. We also showed that organizational learning from errors predicts organizational performance through innovative work behavior that involves active exploration and experimentation. Previous studies also supported the notion that organizational learning and innovation improved the organizational performance by developing a dynamic and proactive vision (Bueno et al., 2010; Glynn, 1996; Hurley and Hult, 1998; Ireland et al., 2001). Furthermore, the results were consistent with previous studies that imply the firm competencies and capabilities to innovate in the presence of learning culture (Chipika and Wilson 2006) Moving further, we found that perceived psychological safety, reduces the anxiety related to interpersonal risks, thus encouraging employees' willingness to learn from errors

\subsection{Theoretical Contribution}

Our study extends the error literature in several ways. Although few studies have demonstrated the positive outcome of error management culture on employee's well-being, recovery of service quality, coworker helping behavior, and employee performance, less attention has been paid to understand how organizational error management culture influences organizational performance via multi mediators. Thus, by theorizing and verifying organizational learning from error and innovative work behavior as a significant intervening variable, this study creates synergies between organizational learning and organizational error management and provides supplementary support to the effectiveness of error management literature in attaining high performance. Since error management is a decisive aspect in dealing with errors in organizations, this study also reinforces the importance of error management culture in recent studies in effectively dealing with errors as compared to error prevention culture. The second worthwhile addition of this study is the inclusion of perceived psychological safety as a moderating variable. In most of the previous studies, perceived psychological safety tends to assume as an intervening variable while in this study we take it as a moderating variable. Worth noting, the result of this study suggested that perceive psychological safety served as a boundary condition influencing organizational learning from errors.

The third contribution was to analyze the impact of error management culture in the service industry. The previous error literature was taken into account the non-service industry such as manufacturing and aviation. Recent studies have begun to examine error management culture in service settings(Guchait, Zhao, Madera, Hua, \& Okumus, 2018). The current study empirically validates the significant impact of error management culture in the service industry. In this way, the current study increases the generalizability of error management literature.

\section{Practical Implications}

The current study has various practical implications. First, by analyzing the impact of management culture on organizational learning from errors, this study suggests that by strengthening error management culture, the organization could make a significant difference. Secondly, many organizations have a punishment-oriented system that rewards success and punishes failure and errors. Under such type of system, employees' productivity is seriously affected since the atmosphere of the organization is not conducive for learning from errors (Tjosvold, Yu, \& Hui, 2004). In light of the given study, managers 
need to establish a safe atmosphere rather than a blaming environment to achieve high performance. This is only done if the management understands the importance of perceived psychological safety for promoting organizational learning from errors. Moreover, management needs to develop such competencies in employees that encouraged them to think positively about errors as a part of organizational learning and innovation.

\subsection{Limitations and Direction for Future Research}

Although this study has practical significance for the service industry, few limitations should be accounted for. First, several unexamined contextual factors affect the relationship between organizational error management culture and organizational performance. For instance, leadership orientation, cultural dimensions are among the few contextual factors that can affect the proposed relationship. The inclusion of contextual factors calls for answers to the following questions that are under what condition might the error management interventions be more effective and how?

Secondly, there are many instances where errors are not managed for instance where speed overrule quality. In such situations, learning from errors is being stifled (Lei, 2018). So, to maintain the balance between the contradictory priorities (speed vs quality), future studies need to examine the complimentary priorities to influence the emergence of errors in the organization.

Thirdly, future studies should incorporate cross-cultural comparisons of error consequences, antecedents, processes to understand their underlying mechanism, (Gelfand, Frese, and Salamon, 2011).

\subsection{Conclusion}

Errors are ubiquitous in organizational life and it is next to impossible to eliminate all kinds of organizational errors. With the view to maintain a competitive position in the global dynamic environment, organizations must encourage their employees to learn and innovate from their errors. By incorporating error management literature with share cognition theory, this current study explains the underlying mechanism of organizational error management culture through multi mediators in achieving organizational performance. The result from the service industry provides the empirical support to our hypotheses that error management culture is indirectly linked to organizational performance through organizational learning from errors and innovative work behavior and perceived psychological safety moderates the relationship between organizational learning from errors and error management culture. These findings also shed light on the importance of constructive orientation toward errors for managers to develop error management culture in their organizations.

\section{References}

Alegre, J., \& Chiva, R. (2008). Assessing the impact of organizational learning capability on product innovation performance: An empirical test. Technovation, 28(6), 315-326.

Amabile, T. M. (1988). A model of creativity and innovation in organizations. Research in Organizational Behavior, 10(1), 123-167.

Arenas, A., Tabernero, C., \& Briones, E. (2006). Effects of goal orientation, error orientation and self-efficacy on performance in an uncertain situation. Social Behavior and Personality: An International Journal, 34(5), 569586.

Argote, L., \& Miron-Spektor, E. (2011). Organizational learning: From experience to knowledge. Organization Science, 22(5), 1123-1137.

Argyris, C. (1976). Single-loop and double-loop models in research on decision making. Administrative Science Quarterly, 363-375.

Argyris, C. (2017). Integrating the Individual and the Organization. Routledge.

Bauer, J., \& Mulder, R. H. (2007). Modeling learning from errors in daily work. Learning in Health and Social Care, 6(3), 121-133.

Bell, E., Bryman, A., \& Harley, B. (2018). Business research methods. Oxford university press.

Bueno E, Aragón JA, Salmador MP, García VJ. Tangible slack versus intangible resources: the influence of technology slack and tacit knowledge on the capability of organizational learning to generate innovation and performance. International Journal of Technology Management 2010;49(4):314-37.

Byrne, B. M. (2013). Structural equation modeling with EQS: Basic concepts, applications, and programming. Routledge.

Campbell, J. P., Gasser, M. B., \& Oswald, F. L. (1996). The substantive nature of job performance variability. Individual Differences and Behavior in Organizations, 258, 299. 
Candranegara, G. (n.d.). Conflict and error management: A case in the furniture industry. 117.

Cannon, M. D., \& Edmondson, A. C. (2001). Confronting failure: Antecedents and consequences of shared beliefs about failure in organizational work groups. Journal of Organizational Behavior: The International Journal of Industrial, Occupational and Organizational Psychology and Behavior, 22(2), 161-177.

Cannon, M. D., \& Edmondson, A. C. (2005). Failing to learn and learning to fail (intelligently): How great organizations put failure to work to innovate and improve. Long Range Planning, 38(3), 299-319.

Cefis, E., \& Marsili, O. (2005). A matter of life and death: innovation and firm survival. Industrial and Corporate Change, 14(6), 1167-1192.

Chillarege, K. A., Nordstrom, C. R., \& Williams, K. B. (2003). Learning from our mistakes: Error management training for mature learners. Journal of Business and Psychology, 17(3), 369-385.

Chiu, C.-M., Hsu, M.-H., \& Wang, E. T. (2006). Understanding knowledge sharing in virtual communities: An integration of social capital and social cognitive theories. Decision Support Systems, 42(3), 1872-1888.

Chipika S, Wilson G (2006). Enabling technological learning among light engineering SMEs in Zimbabwe through networking. Technovation 26 (8):969-979

Coelho, F., \& Augusto, M. (2010). Job characteristics and the creativity of frontline service employees. Journal of Service Research, 13(4), 426-438.

Cooper, R. G. (2000). Product innovation and technology strategy. Research-Technology Management, 43(1), 38-41.

Delaney, J. T., \& Huselid, M. A. (1996). The impact of human resource management practices on perceptions of organizational performance. Academy of Management Journal, 39(4), 949-969.

Dimitrova, N. G., Van Dyck, C., Van Hooft, E. A., \& Groenewegen, P. (2015). Don't Fuss, Focus: The Mediating Effect of On-Task Thoughts on the Relationship between Error Approach Instructions and Task Performance. Applied Psychology, 64(3), 599-624.

Edmondson, A. (1999). Psychological Safety and Learning Behavior in Work Teams. Administrative Science Quarterly, 44(2), 350. https://doi.org/10.2307/2666999

Edmondson, A. C. (2004). Learning from mistakes is easier said than done: Group and organizational influences on the detection and correction of human error. The Journal of Applied Behavioral Science, 40(1), 66-90.

Edmondson, A. C., \& Lei, Z. (2014). Psychological safety: The history, renaissance, and future of an interpersonal construct. Annu. Rev. Organ. Psychol. Organ. Behav., 1(1), 23-43.

Ellis, S., Caridi, O., Lipshitz, R., \& Popper, M. (1999). Perceived error criticality and organizational learning: an empirical investigation. Knowledge and Process Management, 6(3), 166-175.

Fiore, S. M., \& Schooler, J. W. (2004). Process mapping and shared cognition: Teamwork and the development of shared problem models. Team Cognition: Understanding the Factors That Drive Process and Performance, 133-152.

Frese, M., \& Keith, N. (2015). Action errors, error management, and learning in organizations. Annual Review of Psychology, 66, 661-687.

Gatignon, H., Tushman, M. L., Smith, W., \& Anderson, P. (2002). A structural approach to assessing innovation: Construct development of innovation locus, type, and characteristics. Management Science, 48(9), 1103-1122.

Gelfand, M. J., Frese, M., \& Salamon, E. (2011). Cultural influences on error prevention, detection, and management. Errors in Organizations, 273315.

Glynn MA. Innovative genius: a framework for relating individual and organizational intelligences to innovation. Academy of Management Review 1996; 21:1081-111

Goodman, P. S., Ramanujam, R., Carroll, J. S., Edmondson, A. C., Hofmann, D. A., \& Sutcliffe, K. M. (2011). Organizational errors: Directions for future research. Research in Organizational Behavior, 31, 151-176.

Guchait, P., Simons, T., \& Pasamehmetoglu, A. (2016). Error recovery performance: the impact of leader behavioral integrity and job satisfaction. Cornell Hospitality Quarterly, 57(2), 150-161.

Guchait, P., Zhao, X., Madera, J., Hua, N., \& Okumus, F. (2018). Can error management culture increase work engagement in hotels? The moderating role of gender. Service Business, 12(4), 757-778.

Hammond, M. M., Farr, J. L., \& Sherman, P. O. (2011). The role of errors in the creative and innovative process. Errors in Organizations, 67-96.

Hao, Q., Kasper, H., \& Muehlbacher, J. (2012). How does organizational structure influence performance through learning and innovation in Austria and China? Chinese Management Studies, 6(1), 36-52.

Harteis, C., Bauer, J., \& Heid, H. (2012). Research on human fallibility and learning from errors at work: Challenges for theory, research, and practice. In Human Fallibility (pp. 255-265). Springer.

Heimbeck, D., Frese, M., Sonnentag, S., \& Keith, N. (2003). Integrating errors into the training process: The function of error management instructions and the role of goal orientation. Personnel Psychology, 56(2), 333-361.

Helmreich, R. L., \& Merritt, A. C. (2000). Safety and error management: The role of Crew Resource Management. 11.

Hofmann, D. A., \& Frese, M. (2011). Error in organizations. Routledge. 
Homsma, G. J., Van Dyck, C., De Gilder, D., Koopman, P. L., \& Elfring, T. (2009). Learning from error: The influence of error incident characteristics. Journal of Business Research, 62(1), 115-122.

Hülsheger, U. R., Anderson, N., \& Salgado, J. F. (2009). Team-level predictors of innovation at work: a comprehensive meta-analysis spanning three decades of research. Journal of Applied Psychology, 94(5), 1128.

Hurley RF, Hult GT. Innovation, market orientation, and organizational learning: an integration and empirical examination. Journal of Marketing 1998; 62:42-54

Ireland RD, Hitt MA, Camp SM, Sexton DL. Integrating entrepreneurship actions and strategic management actions to create firm wealth. Academy of Management Executive 2001;15(1):49-63

Janssen, O. (2004). How fairness perceptions make innovative behavior more or less stressful. Journal of Organizational Behavior, 25(2), 201-215.

Jones, C. F., \& O’Brien, J. (1991). Mistakes that worked. New York: Bantam Books/Doubleday

Kahn, W. A. (1990). Psychological conditions of personal engagement and disengagement at work. Academy of Management Journal, 33(4), 692-724.

Kanter, R. M. (1983). The change masters: innovation for productivity in the American mode. Simon and schuster.

Karatepe, O. M. (2012). Perceived organizational support, career satisfaction, and performance outcomes: a study of hotel employees in Cameroon. International Journal of Contemporary Hospitality Management, 24(5), 735-752.

Keith, N., \& Frese, M. (2011). Enhancing Firm Performance and Innovativeness Through Error Management Culture. In the Handbook of Organizational Culture and Climate (pp. 137-157). https://doi.org/10.4135/9781483307961.n9

Lei, Z., Naveh, E., \& Novikov, Z. (2016). Errors in Organizations: An Integrative Review via Level of Analysis, Temporal Dynamism, and Priority Lenses. Journal of Management, 42(5), 1315-1343. https://doi.org/10.1177/0149206316633745

Liu, S. S., Luo, X., \& Shi, Y.-Z. (2002). Integrating customer orientation, corporate entrepreneurship, and learning orientation in organizations-in-transition: an empirical study. International Journal of Research in Marketing, 19(4), 367-382. https:/ / doi.org/10.1016/S0167-8116(02)00098-8

McCune, J. C. (1997). Making lemonade. Management Review, 86, 49 -53

Mathieu, J. E., Heffner, T. S., Goodwin, G. F., Salas, E., \& Cannon-Bowers, J. A. (2000). The influence of shared mental models on team process and performance. Journal of Applied Psychology, 85(2), 273.

Nunnally, J. C., \& Bernstein, I. H. (1994). Validity. Psychometric Theory, 3, 99-132.

Nybakk, E., Crespell, P., Hansen, E., \& Lunnan, A. (2009). Antecedents to forest owner innovativeness: An investigation of the non-timber forest products and services sector. Forest Ecology and Management, 257(2), 608-618.

Oldham, G. R., \& Cummings, A. (1996). Employee creativity: Personal and contextual factors at work. Academy of Management Journal, 39(3), 607-634.

Park, Y. K., Song, J. H., Yoon, S. W., \& Kim, J. (2014). Learning organization and innovative behavior: The mediating effect of work engagement. European Journal of Training and Development, 38(1/2), 75-94.

Popper, M., \& Lipshitz, R. (2000). Organizational learning: Mechanisms, culture, and feasibility. Management Learning, 31(2), 181-196.

Putz, D., Schilling, J., Kluge, A., \& Stangenberg, C. (2013). Measuring organizational learning from errors: Development and validation of an integrated model and questionnaire. Management Learning, 44(5), 511-536.

Reason, J. (2000). Human error: models and management. Bmj, 320(7237), 768-770.

Rosenbusch, N., Brinckmann, J., \& Bausch, A. (2011). Is innovation always beneficial? A meta-analysis of the relationship between innovation and performance in SMEs. Journal of Business Venturing, 26(4), 441-457.

Rybowiak, V., Garst, H., Frese, M., \& Batinic, B. (1999). Error orientation questionnaire (EOQ): Reliability, validity, and different language equivalence. Journal of Organizational Behavior: The International Journal of Industrial, Occupational and Organizational Psychology and Behavior, 20(4), 527-547.

Salas, E., Wildman, J. L., Burke, C. S., \& Goodwin, G. F. (2008). Team effectiveness in complex organizations: An overview. In Team Effectiveness in Complex Organizations (pp. 37-50). Routledge.

Sanner, B., \& Bunderson, J. S. (2013). Psychological safety, learning, and performance: A comparison of direct and contingent effects. Academy of Management Proceedings, 2013, 10198. Academy of Management Briarcliff Manor, NY 10510.

Sanner, B., \& Bunderson, J. S. (2015). When feeling safe isn't enough: Contextualizing models of safety and learning in teams. Organizational Psychology Review, 5(3), 224-243.

Schein, E. H. (1985). Defining organizational culture. Classics of Organization Theory, 3, 490-502.

Scott, S. G., \& Bruce, R. A. (1994). Determinants of innovative behavior: A path model of individual innovation in the workplace. Academy of Management Journal, 37(3), 580-607. 
Shih, H.-A., \& Susanto, E. (2011). Is innovative behavior really good for the firm? Innovative work behavior, conflict with coworkers and turnover intention: Moderating roles of perceived distributive fairness. International Journal of Conflict Management, 22(2), 111-130.

Sinkula, J. M., Baker, W. E., \& Noordewier, T. (1997). A framework for market-based organizational learning: Linking values, knowledge, and behavior. Journal of the Academy of Marketing Science, 25(4), 305.

Sitkin, S. B., Sutcliffe, K. M., Roger, G., \& Schroeder, R. G. (1994). Distinguishing control from learning in total quality management: A contingency perspective. Academy of Management Review, 19, 537- 564

Škerlavaj, M., Song, J. H., \& Lee, Y. (2010). Organizational learning culture, innovative culture, and innovations in South Korean firms. Expert Systems with Applications, 37(9), 6390-6403.

Tjosvold, D., Yu, Z., \& Hui, C. (2004). Team learning from mistakes: the contribution of cooperative goals and problem-solving. Journal of Management Studies, 41(7), 1223-1245.

Tucker, A. L., \& Edmondson, A. C. (2003). Why hospitals don't learn from failures: Organizational and psychological dynamics that inhibit system change. California Management Review, 45(2), 55-72.

Unsworth, K. L., \& Parker, S. K. (2003). Proactivity and innovation: Promoting a new workforce for the new workplace. The New Workplace: A Guide to the Human Impact of Modern Working Practices, 175-196.

Ussahawanitchakit, P. (2008). Impacts of organizational learning on innovation orientation and firm efficiency: an empirical assessment of accounting firms in Thailand. International Journal of Business Research, 8(4), 1-12.

Van de Ven, A. H. (1986). Central problems in the management of innovation. Management Science, 32(5), $590-607$.

Van Dyck, C., Frese, M., Baer, M., \& Sonnentag, S. (2005). Organizational error management culture and its impact on performance: a two-study replication. Journal of Applied Psychology, 90(6), 1228.

Vogus, T. J., Sutcliffe, K. M., \& Weick, K. E. (2010). Doing no harm: enabling, enacting, and elaborating a culture of safety in health care. Academy of Management Perspectives, 24(4), 60-77.

West, M. A., \& Anderson, N. R. (1996). Innovation in top management teams. Journal of Applied Psychology, 81(6), 680.

Yuan, F., \& Woodman, R. W. (2010). Innovative behavior in the workplace: The role of performance and image outcome expectations. Academy of Management Journal, 53(2), 323-342.

Zhan, M., \& Hample, D. (2016). Predicting employee dissent expression in organizations: A cost and benefits approach. Management Communication Quarterly, 30(4), 441-471.

Zhao, B., \& Olivera, F. (2006). Error Reporting in Organizations. Academy of Management Review, 31(4), 1012-1030. https://doi.org/10.5465/amr.2006.22528167

Zohoori, M., Mohseni, S., Samadi, B., \& Attarnezhad, O. (2013). The relationship between knowledge sharing and innovation in understand their electronic industry of Iran. Journal of Small Business and Entrepreneurship Development, 1(1), 26-33. 